\title{
Pemetrexed/Pembrolizumab Regimen
}

National Cancer Institute

\section{Source}

National Cancer Institute. Pemetrexed/Pembrolizumab Regimen. NCI Thesaurus. Code C157398.

A regimen consisting of pemetrexed and pembrolizumab that can be used in the treatment of non-small cell lung cancer (NSCLC). 